\title{
EDUCAÇÃO PARA A SUSTENTABILIDADE: UMA ABORDAGEM TRANSDISCIPLINAR.
}

\author{
EDUCATION FOR SUSTAINABILITY: A TRANSDISCIPLINARY \\ APPROACH.
}

\section{EDUCACIÓN PARA LA SOSTENIBILIDAD: UN ABORDAJE TRANSDISCIPLINAR.}

\section{PALAVIZINI, Roseane. ${ }^{1}$}

RESUMO: O Artigo ressalta a Educação Ambiental como oportunidade para a formação da cidadania ambiental nos processos de gestão social nas políticas públicas, propondo a Educação para a Sustentabilidade como Tecnologia Social de formação e capacitação de técnicos e gestores públicos, privados e sociais, com vistas à construção da governança do território. A autora apresenta como fundamentação teórica a transdisciplinaridade, com os pilares propostos por Basarab Nicolescu, ressaltando a implicação da teoria da complexidade, das dimensões de realidade e da lógica do terceiro incluído nos processos pedagógicos e sociais de formação humana $\mathrm{e}$ capacitação. O sujeito transdisciplinar é destacado como referência na formação de técnicos e gestores, cujo propósito é a atuação cooperativa e comprometida com o bem comum e com a sustentabilidade. No modelo apresentado de Educação para a Sustentabilidade, a autora estrutura três pilares: Educação para a Gestão, Educação Tecnológica e Educação Comunicativa, ressaltando a Educação Ambiental e a Educação para a Paz como eixos transversais, responsáveis pela formação ética, no processo de capacitação. Por fim são apresentadas uma concepção de Rede de Sustentabilidade e uma proposta de Avaliação, compondo a concepção final da Educação para a Sustentabilidade. Ao final o artigo propõe uma reflexão sobre educação e humanização.

PALAVRAS-CHAVE: Transdisciplinaridade, Educação Ambiental, Sustentabilidade, Educação para a Paz, Tecnologia Social.

\footnotetext{
${ }^{1}$ Pós-doutorado em Educação para Difusão da Ciência sobre a Antártica (UFRJ), Dra. em Engenharia Ambiental, UFSC (2006). Arquiteta Urbanista, Doutora em Engenharia Ambiental - UFSC, Mestre em Urbanismo - UFBA, Especialista em Planejamento Municipal e Gestão Urbana - UFBA e Gestão Ambiental e Educação Ambiental - UCSal. (palavizini@gmail.com). Urbanist Architect , PhD in Environmental Engineering - UFSC, Master in Urban Planning - UFBA, Town Planning and Urban Management Specialist - UFBA and Environmental Management and Environmental Education - UCSal. palavizini@gmail.com
} 
ABSTRACT: The article emphasizes Environmental Education as an opportunity for the formation of environmental citizenship in public policy social management processes, proposing Education for Sustainability as a Social Technology for training and qualifying private, public and social technicians and managers, aiming to construct the governance of the territory. The author presents the Transdisciplinarity with pillars proposed by Basarab Nicolescu as theoretical basis, highlighting the theory of complexity, dimensions of reality and third party's logics implications encompassed in educational and social processes of human development and qualification. The transdisciplinary subject stands out as a reference to technicians' and managers' training, whose purpose is cooperative performance committed to common welfare and to sustainability. The author structures three pillars in the Education for Sustainability pattern presented: Management Education, Technological Education and Communicative Education, emphasizing Environmental Education and Education for Peace as transverse axes, responsible for ethics training in the qualification process. Finally, a Sustainability Network concept and an Assessment proposal are presented, drawing the Education for Sustainability final design. The article ends with a proposal for the reflection on education and humanization.

KEYWORDS: Transdisciplinarity, Environmental Education, Sustainability, Education for Peace, Social Technology.

RESUMEN: El Artículo resalta la Educación Ambiental como oportunidad para la formación de la ciudadanía ambiental en los procesos de gestión social en las políticas públicas, proponiendo la Educación para la Sostenibilidad como Tecnología Social de formación y capacitación de técnicos e gestores públicos, privados y sociales, buscando la construcción de la gobernabilidad del territorio. La autora presenta como fundamentación teórica la transdisciplinariedad, con los pilares propuestos por Basarab Nicolescu, resaltando la implicación de la teoría de la complexidad, de las dimensiones de realidad y lógica del tercer incluido en los procesos pedagógicos y sociales de formación humana y capacitación. El sujeto transdisciplinar se pone de relieve como referencia en la formación de técnicos y gestores, cuyo propósito es la actuación cooperativa y comprometida con el bien común y con la sostenibilidad. En el modelo presentado de Educación para la Sostenibilidad, la autora estructura tres pilares: Educación para la Gestión, Educación Tecnológica y Educación Comunicativa, resaltando la Educación Ambiental y la Educación para la Paz como ejes transversales, responsables de la formación ética, en el proceso de capacitación. Por fin se presenta una concepción de Red de Sostenibilidad y una propuesta de Evaluación, componiendo la concepción final da Educación para la Sostenibilidad. Al final el artículo propone una reflexión sobre educación y humanización.

PALABRAS-CLAVE: Transdisciplinariedad, Educación Ambiental, Sostenibilidad, Educación para la Paz, Tecnología Social. 


\section{TRANSDISCIPLINARIDADE E EDUCAÇÃO AMBIENTAL}

A Transdisciplinaridade, como uma teoria surpreendente e inovadora, vem lançar importantes desafios ao mundo científico, propondo, de forma aliada com a teoria da Complexidade, a estruturação de um novo paradigma. O paradigma complexo/transdisciplinar prevê que o conhecimento seja engenhado a partir dos referenciais de valorização da diversidade ecológica e cultural, e que o desenvolvimento possa ser construído a partir de uma episteme complexa, capaz de perceber o mundo em suas múltiplas dimensões e interações, na perspectiva de exercer uma melhor compreensão de seus fenômenos e de aprender a conviver com sustentabilidade.

O modelo transdisciplinar de Basarab Nicolesco (NICOLESCU, 1999) ressalta a importância do Sujeito Transdisciplinar, como aquele que possui: Abertura para realizar múltiplas interações com a diversidade que se apresenta em suas relações; Rigor para atuar de forma ética com os princípios pactuados; e Tolerância, que preferimos denominar de Compreensão, para valorizar a diversidade, sendo capaz de interagir de forma construtiva e saudável.

Entendemos que a Educação Ambiental tem como principal finalidade formar o cidadão ambiental para uma relação respeitosa e saudável com os ecossistemas, com a Biosfera e com o Planeta Terra, valorizando a diversidade ecológica e cultural, na perspectiva da construção de um mundo pacífico e sustentável. Nessa perspectiva, a formação do sujeito transdisciplinar se constitui base estruturante para os processos de Educação Ambiental.

Os pilares da transdisciplinaridade propostos por Nicolescu ressaltam ainda: 1) a teoria da complexidade, 2) os diferentes níveis de realidade e 3) a lógica do terceiro incluído. A teoria da complexidade, estruturada por Edgar Morin (MORIN, 2001), com suas múltiplas dimensões de compreensão do mundo, propõe o desenvolvimento da episteme complexa, capaz de perceber a complexidade e a incerteza do mundo. Os diferentes níveis de realidade ressaltam a necessidade de percebermos as diferentes lógicas que determinam diferentes realidades, a partir do reconhecimento da diferença entre as leis que determinam a dimensão macro física e as leis que determinam a 
dimensão quântica. A lógica do terceiro incluído vem demonstrar que existem infinitas possibilidades de interações entre um par de opostos - assim como entre o preto e o branco existem infinitos tons de cinza. Esses três pilares oferecem referência fundamental aos processos de mediação, educação ambiental e construção da sustentabilidade. O primeiro valoriza a formação de uma episteme complexa; o segundo valoriza o respeito às diversidades e suas específicas formas de percepção, sentimento, pensamento e funcionamento. O terceiro propõe a busca do consenso possível, no infinito de possibilidades que surgem em situações de conflitos e oposições, facilitando a mediação.

A partir dessa interação entre Transdisciplinaridade, Educação Ambiental e Sustentabilidade, propomos a Educação para a Sustentabilidade, cujo principal desafio é construir com as sociedades humanas uma perspectiva de ser, viver e conviver de forma harmoniosa na sociedade e com o Planeta Terra.

\section{EDUCAÇÃO PARA A SUSTENTABILIDADE}

O diálogo entre os setores público, social e privado nos processos de planejamento e gestão social tem exigido métodos e técnicas que contemplem a valorização de diferentes lógicas, saberes e percepções, reconhecendo os conflitos como oportunidade de conhecimento da complexidade da realidade e de sua transformação. Nessa perspectiva, a gestão social exige a construção de um espaço cooperativo de convivência, de aprendizado conjunto e de decisões compartilhadas, assumidas de forma integrada. A construção desse espaço de interação entre diferentes visões e interesses, em torno do propósito comum de convivência sustentável entre as pessoas e dessas com os sistemas ecológicos locais, requer um processo de educação que vai além da educação ambiental, exigindo outros conhecimentos metodológicos e conceituais voltados à construção de conhecimentos e atitudes para a realização efetiva da gestão social.

Com essa perspectiva, apresentamos aqui uma concepção de Formação Humana e Capacitação (MATURANA, 1990), baseada nos quatro fundamentos da educação para o século XXI, definidos pela UNESCO: aprender a conhecer, aprender a fazer, aprender a viver e aprender a ser. O Planejamento Sustentável do Território e a Gestão 
Transdisciplinar (PALAVIZINI, 2006) requerem a Educação para a Sustentabilidade. Essa concepção está estruturada em três estratégias de Capacitação: a educação tecnológica; a educação para a gestão; e a educação comunicativa. Nessa concepção a Educação Ambiental e a Educação pra a Paz, assumem um papel transversal e transdisciplinar, de Formação do Ser Humano, atravessando as três estratégias e sintonizando sua "freqüência" ética.

\section{MANDALA DA EDUCAÇÃO PARA A SUSTENTABILIDADE}

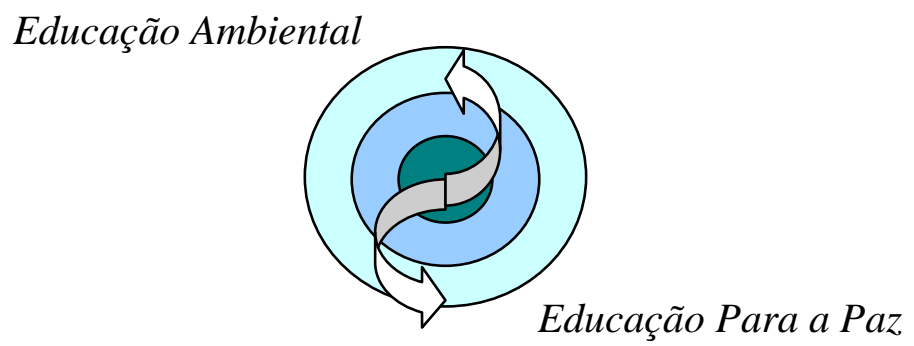

Educação Tecnológica

Educação para Gestão

Educação Comunicativa

A Educação Tecnológica visa auxiliar as comunidades nos caminhos necessários à construção da sustentabilidade em suas atividades econômicas e seus modos de vida. A convivência e a sobrevivência das comunidades estão diretamente relacionadas com o seu conhecimento sobre técnicas de manejo da natureza, adequadas ao seu contexto cultural, social, econômico e ambiental. Quando a técnica produtiva ou a atividade é insustentável, a comunidade requer alternativas compatíveis, não somente com o ambiente, mas também com os limites e potencialidades da cultura local. A esse tipo de tecnologia, passível de replicação junto às comunidades e possível de ser adaptada à sua cultura, com foco na sustentabilidade e no desenvolvimento humano, conceituamos aqui de Tecnologia Social. As tecnologias sociais se apresentam como importantes aliadas nos processos de desenvolvimento da Economia Solidária e da Economia Criativa.

As tecnologias trabalhadas de forma pedagógica com as comunidades facilitam a construção da relação entre a tecnologia, desenvolvida por especialistas, e as práticas comunitárias, agregando sentido a ambos. Essas tecnologias podem ser do tipo 
produtiva, no caso, por exemplo, da agro floresta ou dos sistemas de tratamento de resíduos, ou do tipo construtivas, como as metodologias de planejamento e gestão social.

A educação ambiental e a educação para a paz, trabalhadas transversalmente à educação tecnológica, conformam a base de formação da cidadania ambiental e planetária, fundamentada na ética da paz e da sustentabilidade. Essa base de formação é o alicerce estruturador da capacitação na educação tecnológica, com vistas às transformações necessárias nas formas de manejo dos ecossistemas e de suas riquezas naturais, como a água, as florestas, os solos e as fontes energéticas.

A Educação para a Gestão tem o propósito de contemplar o conhecimento legal e metodológico para uma atuação técnica e social interativa, cooperativa, consciente e qualificada nos processos sociais de planejamento e gestão do território, junto aos colegiados de: bacias hidrográficas, unidades de conservação, municípios, estados e união, tais como: comitês, conselhos, fóruns e comissões. Essa capacitação visa abordar o sentido e o significado desses organismos gestores, os poderes e os limites de sua atuação, os critérios de legitimidade da representação e a formação de uma cultura de atuação cooperativa, interativa, respeitosa da diversidade e solidária. Durante essa capacitação é trabalhada a consciência do papel de cada segmento (público, social e privado), distinguindo a sua lógica de atuação, a sua missão, estratégias e ações.

A educação ambiental e a educação para a paz, trabalhadas transversalmente durante essa capacitação permite uma reflexão ética permanente, uma atuação mais consciente e responsável, promovendo a auto-reflexão sobre as atitudes e abrindo espaço para o diálogo e a mediação. Esse trabalho desenvolvido permanentemente, no cotidiano dos encontros realizados pelos organismos gestores, pretende construir sucessivamente uma cultura de gestão pautada no compromisso com a efetiva participação social na construção da paz e da sustentabilidade em seus respectivos territórios.

A Educação Comunicativa, baseada na Teoria da Ação Comunicativa de Jürgen Habermas, assume o importante papel de promover a comunicação e o intercâmbio entre as pessoas e instituições, distribuindo o poder da informação e motivando a comunidade a participar dos processos sociais, fortalecendo assim alianças e parcerias 
para a construção de projetos e ações cooperativas e solidárias, comprometidas com a sustentabilidade local.

A Educação Comunicativa emerge do reconhecimento da importância dos meios de comunicação como difusores de informação e influenciadores nas opiniões da sociedade. Os processos de comunicação social e comunicação comunitária, com suas respectivas redes, desempenham papel fundamental na construção da governança do território. A qualificação dessa comunicação, a partir de referenciais éticos e científicos, define a importância da educação ambiental e da educação para a paz, como eixos transversais, tendo como principal finalidade difundir uma informação comprometida com a construção de um mundo pacífico, cooperativo, solidário e sustentável. Essa é uma comunicação intencionalmente comprometida com um projeto ético de formação de um cidadão que consiga transitar, respeitosamente, entre as diversidades culturais, religiosas e de visões de mundo.

A Educação Ambiental tem a finalidade de ampliar o conhecimento ambiental da sociedade, contribuindo assim para a formação de uma percepção complexa sobre o ambiente e suas relações. A partir desse conhecimento, torna-se possível refletir sobre as práticas culturais e seu grau de sustentabilidade, abrindo perspectivas locais para práticas sustentáveis de convivência e sobrevivência, fundamentais à construção da sustentabilidade. A função primordial da educação ambiental é o desenvolvimento da consciência ambiental, na busca de uma relação saudável entre a sociedade humana, a Biosfera e o planeta Terra.

A Educação para a Paz está baseada na proposta da Universidade da Paz, onde Pierre Wiel (WIEL, 1990) trabalha a paz pessoal, social e ambiental. O objetivo dessa educação é promover uma ampla reflexão sobre o "espírito de paz" dentro de cada pessoa e em suas relações, alertando para a busca da comunicação e da ação pacífica. No contexto de competição, exclusão e violência que cerca a sociedade brasileira e humanidade em geral, o espírito de guerra e competição se expressa fortemente nas relações interpessoais, nos colegiados de gestão social. Os conflitos no confronto entre diferentes interesses e visões de mundo constituem um dos maiores problemas dos processos de planejamento e gestão social do território. Seja pela falta de compreensão ou mesmo pelo desrespeito às diferenças, os diferentes segmentos estabelecem conflitos, entre saberes e percepções, que necessitam de mediação e condução pacífica. 
A educação para a paz, como alternativa pedagógica, oferece oportunidades técnicas e metodológicas para essa mediação, facilitando a construção coletiva de consensos e pactos possíveis.

A Educação para a Sustentabilidade nos remete ainda para a idéia-chave de Sustentabilidade das Ações, buscando a construção da Rede de Sustentabilidade a partir de três pontos de conexão e convergência: o Humano, com a capacitação de educadores, técnicos e lideranças, para atuarem como Agentes Atratores da Rede; o Institucional, com a articulação trans institucional, relacionando instituições públicas, sociais e privadas, para uma atuação cooperativa e solidária, sob forma de convênios, acordos e projetos comuns, formalizando a interação entre pessoas e instituições; e o Operacional, definido e estruturando centros de referência, equipando locais estratégicos como, escolas, associações, empresas, instituições públicas, fundando nesses espaços pontos de convergência da Rede, para viabilizar o acesso das informações e o diálogo entre comunidades.

\section{MANDALA DA REDE DE SUSTENTABILIDADE}

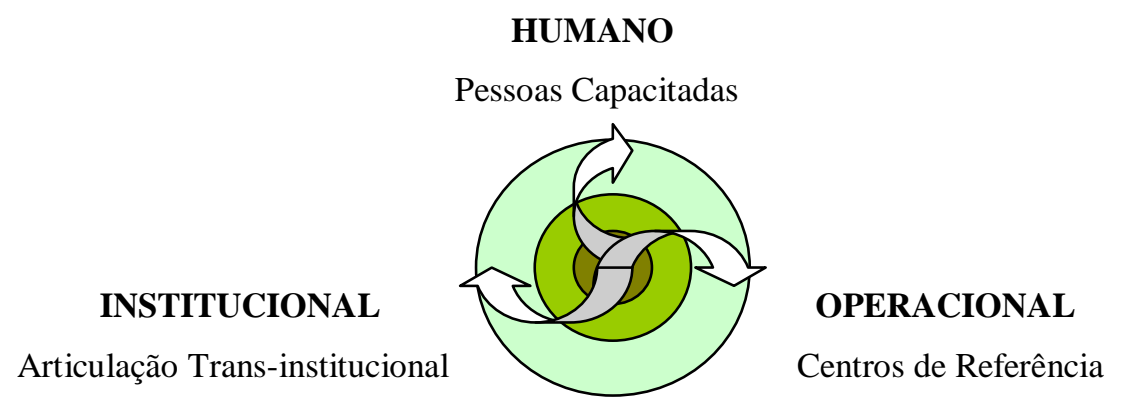

A Educação para a Sustentabilidade requer um conjunto de metodologias, articuladas entre si, envolvendo diferentes técnicas e atividades, planejadas de acordo com as especificidades de cada realidade trabalhada.

O processo de avaliação deve contemplar a valorização das múltiplas percepções, a partir de cada pessoa, alcançando uma reflexão coletiva e produtora de sínteses capazes de orientar um novo aprendizado e uma nova atuação. Com a finalidade de valorizar a diversidade de percepções e emoções, o processo de avaliação deve utilizar técnicas e dinâmicas que permitam a expressão individual e o compartilhar coletivo, a exemplo da dinâmica do Coração que Fala. Essa dinâmica é baseada em um ritual indígena, que utiliza um "bastão" simbólico, especialmente construído para essa 
finalidade. A pessoa que está com o bastão deve falar com a força do seu coração, e deve ser ouvida por todos, também com o coração de quem ouve, sem ser interrompido. Essa dinâmica abre o espaço da escuta sensível do grupo, valorizando a contribuição de cada participante, sem contesta-lo ou afirmá-lo, mas reconhecendo-o como legítimo em sua percepção e emoção.

Os projetos de Educação para a Sustentabilidade devem prever a estrutura de avaliação em três estratégias: 1) a Avaliação de Processo; 2) a Avaliação de Resultados; e 3) a Avaliação de Impacto.

\section{MANDALA DAS ESTRATÉGIAS DE AVALIAÇÃO}

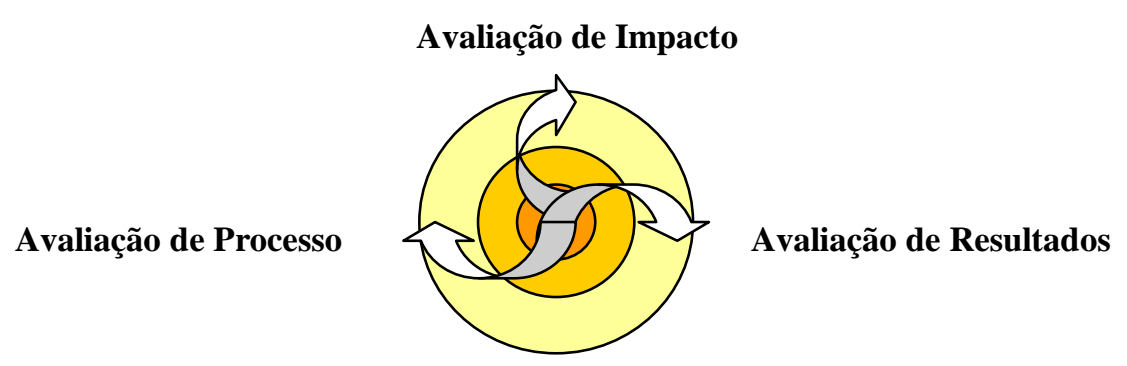

A Avaliação de Processo é realizada a partir da avaliação de cada atividade proposta, verificando seus métodos e resultados parciais, a partir dos indicadores propostos para cada uma delas. Essa avaliação permite a realização de ajustes na atividade, identificando as anomalias do processo, que implicam diretamente ou indiretamente nos resultados esperados e buscando o bom resultado do conjunto.

A Avaliação de Resultados é realizada a partir da avaliação dos objetivos, com seus respectivos indicadores e meios de verificação. Nessa etapa de avaliação os resultados são medidos e refletidos no sentido do alcance do objetivo maior do projeto, revelando as estratégias e objetivos bem sucedidos e aqueles que necessitam de reformulações ou complementações. O processo avaliativo é visto como oportunidade de melhoramento contínuo.

A Avaliação de Impacto, também realizada a partir dos objetivos propostos, com seus indicadores e meios de verificação, buscam identificar os "rastros" de permanência ou continuidade das ações do Projeto, sua reverberação para além do alcance de ação direta do Projeto e de seus objetivos. Nessa etapa são verificados os elementos de 
permanência, multiplicação e recriação, a partir das ações realizadas pelo Projeto e que foram capazes de estruturar uma rede contínua de repercussões criativas, renováveis e renovadoras.

A Educação para a Sustentabilidade destaca como maior desafio aos processos sociais e ambientais, o desenvolvimento humano e as transformações pessoais e profissionais, partindo da ética que escolhemos para construir o mundo que desejamos, e a partir daí, escolhendo as teorias aliadas, e com elas, as metodologias e métodos para o desenvolvimento do nosso trabalho. A questão aqui ressaltada é a nossa consciência do mundo que estamos construindo com a nossa pesquisa, com as nossas ações e com a nossa forma de viver, conviver e sobreviver. É desse contexto que emerge a concepção da Educação para a Sustentabilidade. Afinal, quem não está a serviço de sua própria ética, certamente, está a serviço da ética de alguém.

\section{CONSIDERAÇÕES FINAIS}

A construção da convivência sustentável entre as sociedades humanas os ecossistemas, a Biosfera e o planeta Terra é o principal desafio da Educação Ambiental. Com esse mesmo propósito vem sendo desenvolvidas tecnologias limpas e tecnologias sociais que visam contribuir com a efetividade dessa missão. Com todo o conhecimento ambiental conquistado, com os avanços da ciência, com as constatações dos desequilíbrios ambientais globais e o risco eminente da não permanência da espécie humana sobre esse planeta, ainda resta um longo caminho para alcançarmos as consciências e, principalmente, as mudanças de hábito.

Essa reflexão nos faz perguntar: então o que falta? Como poderemos contribuir realmente com a humanização? Será que precisamos refletir sobre nossas diferentes visões de mundo? Afinal, qual é o mundo que você está ajudando a construir? Que educação precisamos empreender para despertar a humanidade para a ética da vida, da saúde, da compreensão, da paz e da sustentabilidade?

Essas são algumas reflexões que permanecem. Ao nos aliarmos ao paradigma complexo/transdisciplinar estamos propondo uma educação para a expansão da consciência, para a valorização da diversidade ecológica e cultural e acima de tudo, para 
a humanização e a construção de uma relação sustentável e saudável das sociedades humanas com o planeta Terra.

\section{REFERÊNCIAS BIBLIOGRÁFICAS}

HABERMAS, Jüugen. Teoria de La Accion Comunicativa. 2 Tomos. Madrid: Tourus, 1987.

LEI FEDERAL 9.795/ abril 1999 - Política Nacional de Educação Ambiental.

LEI FEDERAL 9.433/ jan. 1997 - Política Nacional de Recursos Hídricos.

LEI FEDERAL 9.985/ julho 2000 - SNUC - Sistema Nacional de Unidades de Conservação.

LEI FEDERAL 10.257 julho 2001 - Estatuto da Cidade.

MATURANA, Humberto; VARELA, Francisco. Autopoiésis and Cognition. Dordrecht, Ho: D.Reidel, 1980.

MATURANA, Humberto. El Sentido del Humano. Santiago: Dolmen, s/d.

MATURANA, Humberto; REZEPKA, Sima Nisis de. Formação Humana $e$ Capacitação. Trad. Jaime A. Clasen. Petrópolis: Vozes, 2000.

MORIN, Edgar. Os sete saberes necessários à educação do futuro. Trad. Catarina Eleonora da Silva e Jeane Sawaya. São Paulo: Cortez; Brasília: UNESCO, 2001.

La methode V - L humanite de L humanite. Lisboa: Seuil, 2001.

NICOLESCU, Basarab. O manifesto da transdisciplinaridade. São Paulo: TRIOM, 1999.

PALAVIZINI, Roseane. Gestão Transdisciplinar do Ambiente: Uma Perspectiva aos Processos de Planejamento e Gestão Social no Brasil. Tese de Doutorado do Programa de Pós-Graduação em Engenharia Ambiental - UFSC, Florianópolis, 2006.

PRIGOGINE, Ilya, STENGERS, Isabelle. A nova aliança. Brasília: Editora da Universidade de Brasília, 1984. 248p.

SILVA, Daniel J. O Paradigma Transdisciplinar: uma perspectiva metodológica para a pesquisa ambiental. In: PHILIPPI, Arlindo (Eds), Interdisciplinaridade em Ciências Ambientais. São Paulo: Signus, 2000.

WIEL, Pierre. A Arte de Viver em Paz: UNESCO, 1990. 